\title{
SOCIEDADE DE RISCO, MÍDIA E ORDENAMENTO JURÍDICO
}

\author{
Kelly Cardoso da Silva ${ }^{1}$
}

\begin{abstract}
RESUMO: A globalização acarretou mudanças de ordem ideológica, científica-tecnológica e, sobretudo, social. Como resposta a estas mudanças e a modernidade tardia, nasce uma sociedade de risco, incertezas, insegurança e medo, a qual é potencializada pela influência dos meios de comunicação, ocasionando reflexos no ordenamento jurídico. Assim, essa sociedade de risco clama pela solução das novas demandas, exigindo do Estado uma célere ação como forma de contenção da moderna problemática e da criminalidade. Para atender os anseios sociais, o Estado lança mão do Direito Penal, que sofre um nítido processo de expansão em suas bases e estruturas, originando um forte conflito com o modelo penal clássico. Com isso, o Direito, que deveria ser um instrumento de garantia do cidadão, encontra-se em um caminho inverso, ampliando seu âmbito de atuação, antecipando a intervenção punitiva, reduzindo ou até mesmo suprimindo as formalidades e garantias penais e processuais penais, na tentativa de reduzir/suprimir as ameaças concretas ou simbólicas dessa nova sociedade.
\end{abstract}

Palavras-chave: Sociedade. Mídia. Direito.

\section{SOCIETY OF RISK, MEDIA AND LEGAL ORDINANCE}

\begin{abstract}
Globalization brought changes of ideological, scientific-technological and, above all, social order. In response of these changes and the late modernity, a society of risk, uncertainty, insecurity and fear is born, which is enhanced by the influence of the mass media, bringing about changes in the legal order. Thus, this society of risk cries out for the solution of the new demands, demanding of the State a swift action as a form of containment of the modern problematic and of the criminality. In order to meet social anxieties, the State uses criminal law, which undergoes a clear process of expansion in its bases and structures, causing a strong conflict with the classic criminal model. By these means, Law, which should be an instrument of citizen's guarantee, is in an inverse way, broadening its scope of action, anticipating punitive intervention, reducing or even suppressing criminal formalities and guarantees attempt to reduce / suppress the concrete or symbolic threats of this new society.
\end{abstract}

Key-words: Society. Media. Law.

\section{INTRODUÇÃO}

A globalização é uma fase do capitalismo, que constitui um desdobramento do comércio internacional que vinha se desenvolvendo desde o mercantilismo. Constitui uma necessidade do capitalismo para que ele mantenha seu processo de produção, pois no

\footnotetext{
${ }^{1}$ Possui graduação em Direito - Faculdades Unificadas de Foz do Iguaçu (UNIFOZ), pós-graduação pela Escola da Magistratura do Estado do Paraná, mestrado em Direito das Relações Sociais pela Universidade Internacional
} 
momento em que o mercado nacional não é suficiente há uma necessidade de expansão de sua área de atuação, ocasionando uma nítida pretensão de descolamento com as soberanias nacionais, subordinando, em escala mundial, todas as demais manifestações da humanidade à sua lógica.

Assim, registrou o mundo registrou transformações imediatas e incontroláveis, ocasionando o surgimento novos riscos, fazendo com que a sociedade se caracterizasse por sua insegurança e medo, principalmente no que se refere ao avanço da criminalidade e de suas novas formas.

Esses novos riscos, criados ou acentuados pela globalização e expandidos pelos meios de comunicação, fazem com que os indivíduos atingidos clamem por solução a essas novas demandas, exigindo do Estado uma célere resposta de contenção da moderna problemática.

Dessa feita, para atender essa sociedade de risco, o Estado lança mão de um Direito Penal expansivo e preocupado somente com uma prevenção e repressão exacerbadas, submetendo os indivíduos a políticas de segurança pública que aniquilam direitos e garantias fundamentais.

\section{A SOCIEDADE DE RISCOS, INCERTEZAS, INSEGURANÇAS E MEDO}

O sociólogo alemão Ulrich Beck (BECK, 2011) desenvolveu um modelo teórico em torno da concepção da sociedade de risco, rapidamente incorporada depois das reflexões sobre a evolução atual do Direito não só no âmbito penal, mas também em outras esferas do ordenamento jurídico.

Segundo o referido autor, a produção social de riqueza em uma modernidade tardia é acompanhada sistematicamente pela produção social de riscos, ocasionando uma relativização de conceitos até então utilizados, como "sociedade industrial" ou "sociedade de classes". É a própria sociedade tardiamente moderna que cria tais riscos, mas é justamente ela que procura incansavelmente solucionar esses problemas. "O processo de modernização torna-se 'reflexivo", convertendo-se a si mesmo em tema e problema" (BECK, 2011, p. 23-24) 2.

Desde a década de 70, reconhece-se em países de Terceiro Mundo uma modernidade tardia, sob a escusa de que somente com uma evolução científica-tecnológica, poder-se-ia acalçar a riqueza social, libertando-se da pobreza e miséria, a que estão enclausurados.

Tres Fronteras, mestrado em Direito Público pela Unisinos é doutoranda em Sociedade, Cultura e Fronteiras pela Universidade Estadual do Oeste do Paraná (UNIOESTE). Contato: kellycardosoo@ hotmail.com 
Todavia, esquece-se que tal processo possui efeitos colaterais, que são potencializados pela própria mente humana.

A transição de "sociedade industrial de classes" para a "sociedade de risco" é fenômeno ainda em trâmite, não podendo ser compreendido sob a ótica das antigas categorias sociais, as quais estão sendo reformuladas.

Ao mesmo tempo em que essas categorias estão passando por esse processo de reestruturação, a sociedade de risco possui um ponto em comum com a sociedade de classes, pois enquanto nesta indaga-se como pode ser legítima ao distribuir a riqueza de forma desigual, naquela também se questiona como evitar as ameaças criadas sem comprometer o processo de modernização. Em outras palavras, nas duas categorias, o efeito colateral, apesar de socialmente prejudicial, é legítimo. Assim, a produção social da riqueza é indissociável da produção social de riscos.

Imperioso salientar que a existência de riscos não consiste uma novidade, nem na Europa de Ulrich Beck, nem no Brasil. Todavia, estar-se a se falar de novos riscos diversos daqueles até então conhecidos, pois possuem dimensões globais com características destrutivas advindas da industrialização. Os perigos são disseminados, não estando restritos aos locais onde foram produzidos.

\footnotetext{
Os riscos da modernização cedo ou tarde acabam alcançando aqueles que o produziram ou que lucram com eles. Eles contêm um efeito bumerangue, que implode o esquema de classes. Tampouco os ricos e poderosos estão seguros diante deles. Isso não apenas sob a forma de ameaças à saúde, mas também como ameaças à legitimidade, à propriedade e ao lucro (BECK, 2011, p. 27).
}

As ameaças advindas da sociedade do risco, tornam-na uma sociedade catastrófica, sendo que sua gestão pode abranger uma reorganização do poder e da responsabilidade. Assim, com o avanço dos riscos sociais, aumentam-se cada vez mais as promessas de segurança estatal. Analisando a teoria de Ulrich Beck, tem-se que sociedade de risco (CALLEGARI, WERMUTH, 2010, p. 14),

${ }^{2}$ Para Ulrich Beck, riquezas sociais são bens de consumo, renda, oportunidades educacionais, propriedade etc. (BECK, 2011, p. 32). 
sociedade de risco, que está marcada por ameaças e debilidade que projetam um futuro incerto.

Cita-se como características primordiais desse modelo sociológico, a ampliação das fronteiras da punibilidade, o aumento da orientação e prevenção e a transformação no papel que se atribui ao controle penal de conflitos. $\mathrm{O}$ debate sobre a influência do referido modelo no âmbito jurídico é consideravelmente vasto, questionando-se a importância da intervenção penal para a prevenção de riscos decorrentes de transformações estruturais na sociedade que é dita como sendo de risco.

Assim, partindo do paradoxo de que o risco afeta de modo involuntário as pessoas, mas tem sempre sua origem em uma decisão humana, tem-se que esta situação de irresponsabilidade se produz como consequência de múltiplas ações individuais e, por outro lado, pela afetação do próprio ser humano em sociedades diferenciadas (BUERGO, 2001, p. 28). Desta forma, tem-se que os seres humanos produzem os riscos e são destes as maiores vítimas.

O desconhecimento acerca das ameaças ou dos mecanismos que podem produzir danos é, sem dúvida, central no conceito da sociedade de risco, pois se supõe que na sociedade moderna as pessoas estão produzindo para si mesmas seu próprio perigo. $\mathrm{O}$ atual nível de desenvolvimento tecnológico da sociedade não é compreendido de maneira completa, fazendo que o futuro seja imprevisível.

Diante dessa imprevisibilidade, além dos riscos concretos sentidos pela população, tem-se ainda uma sensação de insegurança subjetiva que pode existir independentemente da presença de perigos reais. Assim, a demanda normativa busca não somente a proteção objetiva frente a riscos e perigos, mas a possibilidade de assegurar a proteção, a confiança ou segurança, convencendo os membros da sociedade que estão livres de temores. $\mathrm{O}$ risco depende da consciência e intensidade que se tenha dele,

Contudo, essa demanda torna-se problemática quando o destinatário de todo o clamor é o ordenamento jurídico, utilizando-se o Poder Legislativo de meios de controle de novos perigos. O Estado, em vez de sanar a causa da insegurança social lançando mão de políticas públicas que atendam sua população, acaba por optar em dar uma solução rápida e simbólica: o Direito Penal.

Gera-se uma mudança de perspectiva nesse ramo do direito, que deveria ser considerado como ultima ratio, sendo a última opção do Estado na busca de proteção dos bens jurídicos, para um modelo de direito de Estado intervencionista. E é justamente nesse 
ponto que o conceito de sociedade de risco transpassa para a análise jurídica, criando-se um Direito Penal do risco.

O Direito Penal do risco é uma criação conceitual crítica com a que se designaria uma forma de desenvolvimento e um conjunto de modificações estruturais pelas quais o Direito Penal se adaptou. Deste ponto de vista mais crítico, com as consequências que a nova penetração da ideia de risco no Direito Penal traz consigo, a questão crucial não seria tanto o surgimento do Direito Penal de risco, mas quais são as consequências dessa criação e até que ponto estas podem supor uma autêntica crise jurídica (BUERGO, 2001, p. 28).

Neste sentido, quando mais grave for o dano temido, mais justificado se considera a atuação do Direito Penal em sua qualidade de resposta mais dura do controle social. Recorrese ao legislador frequentemente e cada vez com maior urgência buscando proteção penal frente aos problemas levantados nesta sociedade de risco.

Já Zygmunt Bauman sugere a substituição da já tão mencionada expressão "sociedade de risco" por "sociedade da incerteza" (BAUMAN, 1999, p. 129-130). Segundo o autor, as incertezas nascidas na modernidade, acentuadas pela sociedade de consumo, não poderiam ser calculadas nem espacial nem temporalmente dos atores sociais, já que se expandem e complexificam. A incerteza é tida como o habitat natural da vida humana, e o principal motor da atividade dos indivíduos é a esperança de dela escapar.

Para o referido sociólogo, essas incertezas ocasionam um enorme medo e insegurança na sociedade e como implicação desses sentimentos, tem-se a ampliação da preocupação com as novas formas de criminalidade.

Mesmo com a adoção de expressão diversa daquela adotada por Ulrich Beck, Bauman concorda que por receio dessa criminalidade, o Direito Penal é eleito como instrumento para contrapor à pretensão por segurança, o que emana, do entendimento de que a utilização de medidas criminais é mais eficaz do que medidas de política social ou econômica, ou, ainda, de medidas decorrentes da intervenção de outros ramos do Direito. Inverte-se a finalidade do Direito Penal, que deixa de ter caráter subsidiário, passando a ser prima ratio ${ }^{3}$.

Já Silva-Sanchez afirma que a atual sociedade pode ser definida como a "sociedade da insegurança ou sociedade do medo", afirmando que a existência subjetiva dos riscos é evidentemente maior do que a própria existência objetiva destes (SÁNCHEZ, 2002, p. 75).

\footnotetext{
${ }^{3}$ Nas palavras de André Luís Callegari e Roberta Lofrano Andrade, “.... torna-se possível a afirmação de que a vida na Sociedade do Risco nos torna suscetíveis a riscos até então desconhecidos e que fogem da capacidade humana de controle. Nesse contexto, todos os aspectos elencados acima acabarão por influenciar o Direito Penal, pressionando-o a uma situação expansionista a fim de que se alcance segurança." (CALLEGARI, et al., 2011, p. $16)$.
} 
Denota-se que as três expressões utilizadas por Beck, Bauman e Silva-Sanchez não são antagônicas, mas se complementam considerando que a sociedade moderna apresenta riscos objetivos/concretos quanto riscos subjetivos, advindos de uma evolução científicatecnológica. Ademais, tanto a sociedade do risco, como a sociedade da incerteza, sociedade da insegurança/medo, possuem a mesma consequência: caracterizar uma formação social e influenciar a criação e aplicação de seu ordenamento jurídico.

Conforme já explicitado, os riscos criados ou acentuados pela modernidade ocasionam uma reação irracional por parte dos atingidos, gerando a sensação de insegurança, fazendo com que a sociedade se submeta voluntariamente a políticas de segurança pública elaboradas em detrimento de interesses individuais.

Esse sentimento de insegurança proveniente do modelo de "sociedade de risco" é criado pelo momento histórico, político e econômico vivenciado. Entretanto, é acentuado pelos meios de comunicação ${ }^{4}$. A influência da mídia na população pode tornar-se negativa ao divulgar informações incompletas, tendenciosas, obscuras e sensacionalistas, que trazem um grande malefício aos julgamentos e a prática legislativa. E nesse sentido, os meios de comunicação conseguem impor à sociedade uma forma única de analisar os seus problemas, potencializando o perigo social e atingindo um efeito de mobilização das camadas populares sem as corretas informações a respeito de um determinado tema.

Acerca dos meios de comunicação Maiquel Ângelo Dezordi Wermuth preleciona que a sociedade globalizada é influenciada cada vez mais pela mídia, formadora de opinião.

\begin{abstract}
A busca do sensacional e do espetacular, do furo jornalístico, é o princípio de seleção daquilo que pode e daquilo que não pode ser mostrado, o que é definido pelos índices de audiência - ou seja, pela pressão do campo econômico, do mercado, sobre os jornalistas. E as imagens, aliadas às legendas que dizem o que é preciso ler e compreender, produzem o efeito de real, ou seja, fazem ver e fazem crer no que fazer ver. (...) O perigo decorrente disso é justamente o fato de que mídia de massa impõe ao conjunto da sociedade uma forma bastante peculiar de enxergar os "problemas sociais", fruto de uma lógica mercadológica que busca, a todo custo, a audiência, ou seja, o sucesso comercial. A potencialização desse perigo ocorre em virtude do fato de que o poder de "evocação" exercido pela mídia tem efeitos de “mobilização (WERMUTH, 2011. p. 29).
\end{abstract}

\footnotetext{
${ }^{4}$ Segundo Ripollés, "La preeminência de los espacios dedicados a la crônica criminal en los más diversos medios de comunicación, dondo ya no es extraño que ocupe los primeros titulares, tiene que ver sin Duda, aunqye no exclusivamente, con el eco que tales informaciones suscitan en capas amplias de la población. Ello há permitido que el miedo o la preocupación por el delito se hayan afincado en la agenda social entre los asuntos más relevantes y, lo que es aún más significativo, que la persistência y arraigo de tales actitudes se haya convertido en um problema social en sí mismo. En efecto, resulta fácil apreciar que um buen número de programas de intervención penal son diseñados no tanto para reducir efectivamente el delito, cuanto para disminuir las generalizadas inquietudes sociales sobre la delincuencia”. (RIPOLLÉS, 2007, p. 75-76). Nesse sentido Alessandro Baratta (BARATTA, 2004. p. 165-166).
} 
Desta forma, o dano na elaboração do ordenamento jurídico é claro, ocorrendo a criminalização de condutas de forma instantânea sem debates ou estudos aprofundados. Leis penais são criadas ou alteradas em virtude da notícia do momento. Penas tornam-se mais rigorosas mesmo diante de um sistema carcerário falido e da ineficiência das políticas públicas.

Em uma sociedade de risco, no combate as modernas ameaças, tenta-se repropor a ordem - e não a justiça - como valor supremo. A lei deveria restaurar a ordem aumentando os níveis punitivos e penalizando, com severidade, os criminosos perigosos ou reincidentes. Nenhuma clemência deve ser aceita. A proposta é dar uma resposta concentradamente retributiva. Busca-se eliminar o resultado, sem dar o tratamento devido a causa.

No Brasil, pode-se citar algumas leis que foram criadas de forma imediata a partir da ampla divulgação pelos meios de comunicação de um determinado fato:

\begin{tabular}{|c|c|c|}
\hline LEI & DATA & MOTIVAÇÃO \\
\hline Lei $n^{\circ} 2.033$ & 20.09 .1871 & $\begin{array}{l}\text { Criminalizou o homicídio culposo depois de um acidente ferroviário na } \\
\text { cidade de Jundiaí-SP. }\end{array}$ \\
\hline Lei $n^{\circ} 3.311$ & 15.10 .1886 & $\begin{array}{l}\text { Criminalizou o delito de incêndio após a ocorrência de dois episódios na } \\
\text { cidade do Rio de Janeiro-RJ. }\end{array}$ \\
\hline Lei $n^{\circ} 8.072$ & 25.07.1990 & $\begin{array}{l}\text { Dispõe sobre os crimes hediondos e as restrições legais a eles aplicadas, } \\
\text { posteriormente às extorsões mediante sequestro de Abílio Diniz e Ricardo } \\
\text { Roberto Medina. }\end{array}$ \\
\hline Lei ${ }^{\circ} 8.930$ & 06.09 .1994 & $\begin{array}{l}\text { Considerou hediondo o homicídio qualificado e o praticado em atividade } \\
\text { típica de grupo de extermínio, em razão da morte da atriz Daniela Perez e } \\
\text { das chacinas da Candelária e Vigário Geral. }\end{array}$ \\
\hline Lei ${ }^{\circ} 9.455$ & 07.04 .1997 & $\begin{array}{l}\text { Criminalizou a tortura após a filmagem de torturas praticada por policiais } \\
\text { em Diadema (caso Favela Naval), transmitidas por redes de televisão por } \\
\text { todo o país. }\end{array}$ \\
\hline $\begin{array}{l}\text { Lei } \mathrm{n}^{\circ} 9.677 \text { e } \\
\text { Lei } \mathrm{n}^{\circ} 9.695\end{array}$ & $\begin{array}{ll}02.07 .1998 & \mathrm{e} \\
20.08 .1998 & \end{array}$ & $\begin{array}{l}\text { A primeira aumentou forma absurda a sanção penal e a segunda } \\
\text { considerou crime hediondo o delito de falsificação, corrupção, adulteração } \\
\text { ou alteração de produto destinado a fins terapêuticos ou medicinais, em } \\
\text { virtude da falsificação de anticoncepcionais ocorrida a nível nacional. }\end{array}$ \\
\hline Lei $\mathrm{n}^{\circ} 12.737$ & 30.11 .2012 & $\begin{array}{l}\text { Também conhecida como Lei Carolina Dieckmann, promoveu alterações } \\
\text { no Código Penal Brasileiro tipificando os chamados delitos ou crimes } \\
\text { informáticos, após a invasão de dispositivo eletrônico da atriz Carolina } \\
\text { Dieckmann, com o consequente vazamento e divulgação de suas imagens } \\
\text { pessoais. }\end{array}$ \\
\hline
\end{tabular}

Tal situação, longe de ser algo excepcional, somente demonstra que o sistema jurídico está perdendo parte de sua consistência. Ripollés preleciona que a experiência cotidiana do povo, sua percepção imediata da realidade e os conflitos sociais, passou a ser um fator de 
primeira importância na hora de elaborar as leis penais, e pugna por ser também na aplicação legal. A novidade, contudo, não é que tais experiências e percepções condicionem a criação e aplicação do Direito, algo legítimo em toda a sociedade democrática, mas

el que demanden ser atendidas sin intermediários, sin la interposición de núcleos expertos de reflexión que valoren las complejas consecuencias que toda decisión penal conlleva. Los portadores de esos nuevos conocimientos son la opinión pública creada por los médios populares de comunicación social, las victimas o grupos de víctimas y, en último término, el pueblo llano (RIPOLLÉS, 2007, p. 80).

Afirma Nilo Batista (BATISTA, 2004, p. 83-85), enfatizando o papel que os meios de comunicação está exercendo no Brasil, que

\begin{abstract}
Antes de mais nada, a mídia não apenas se adequou, mas colaborou definitivamente na expansão de uma mentalidade penal que imobiliza toda riqueza e complexidade dos conflitos sociais na episteme binária e simplória do infracional: é assim que a questão da reforma agrária pode ser reduzida a delito contra a propriedade de integrantes do MST, por um lado, e aos 'excessos' policiais contra eles (chacinas) de outro. Ao processo de desmerecimento do setor público, funcional para implementação das privatizações, correspondeu a criminalização midiática da vida política. No núcleo ideológico deste movimento está não apenas um discurso criminológico único - que assume preponderância e influência muito superior ao acadêmico, e cujas toscas contradições e inconsistências não encontram canal de questionamento - mas principalmente uma novidade perigosa: o exercício direto de funções características das agências policiais do sistema penal.
\end{abstract}

A mídia além de exercer as características das agências do sistema penal, transgredindo direitos e garantias penais e processuais e aumentando a sensação de insegurança da população, assim o faz com base na liberdade de expressão e pelo direito de informação, que acabam se tornando prioritários em face de direitos individuais e coletivos de maior importância.

Note-se que a imprensa faz com que sociedades que não possuam problemas específicos de criminalidade (terrorismo, por exemplo) comecem a se preocupar em razão da constante e ilimitada divulgação, a qual propaga o medo e o terror por todas as partes do mundo. Um exemplo que pode ser citado é o atentado americano do dia 11 de setembro de 2001. A partir dessa data, tomou-se conhecimento de um risco existente, mas também criou-se um risco subjetivo nas mentes de toda uma população global.

Os meios de comunicação transmitem uma imagem que confunde o risco que está próximo com aquele que está distante. Aumenta demasiadamente a sensação de insegurança e impotência, aproximando os indivíduos da cena do crime (MORAES, 2009, p. 52). 
Entretanto, verdade seja dita, a sensação de medo e insegurança da sociedade não é causada exclusivamente pela mídia, mas também pelo acréscimo da criminalidade, tanto a de rua quanto a organizada. Os meios de comunicação, na realidade, potencializam os medos advindos de acontecimentos sociais. Esses medos difundidos são existenciais ou meramente comunicacionais. Some-se a isto o fato de haver uma desconfiança de que os órgãos institucionalizados de controle social não possuíam capacidade de reação, presos às dificuldades de suas engrenagens, atados à sua própria burocracia, impossibilitados, portanto, de solucionar, de forma eficaz, às ações delinquenciais.

Com isso, chegou-se ao quadro de que toda a sociedade deveria ser mobilizada para a exterminação do tríplice mal: crime, criminalidade e criminoso. E a partir dessa finalidade, era indispensável, com urgência, o recrudescimento da lei penal, a única capaz de resolver a questão envolvendo os homens desviados.

Ressalta Antonio García-Pablos de Molina (MOLINA, 1989, p. 328), que o medo do cidadão de tornar-se vítima de crime acarreta

\begin{abstract}
desconfiança para com risco de notórios excessos defensivos, modifica os estilos de vida de amplos setores da população gerando contínuos comportamentos não solidários para com outras vítimas e desencadeia, logicamente, uma política criminal passional, baseada num rigor desmedido no apelo à pena, que põe em perigo as conquistas racionais e humanitárias de nosso tempo. Em momentos de crise, o medo ao delito costuma ser manipulado por opções políticas concretas, capazes de instrumentalizar, a seu serviço, conhecidos mecanismos psicossociais.
\end{abstract}

Além disso, a invocação ao perigo e a sentimentos intensos de temor, somados à incriminação de certos grupos ou minorias desviados constituem uma poderosa arma do Estado, desviando os olhares de outros problemas sociais mais relevantes, impulsionando somente um maior rigorismo da política criminal.

Por fim, não se questiona a legitimidade da sociedade em exigir segurança, até porque é um direito fundamental trazido pela Constituição Federal. O que é questionável, todavia, é se o Direito Penal consiste no instrumento correto para atender a todos esses anseios da população.

\title{
CONCLUSÃO
}


A forma de interpretar o mundo foi alterado pelas transformações experimentadas pela sociedade moderna e pelo capitalismo. A modernidade tardia, principalmente em países de Terceiro Mundo, faz com que surjam riscos, medos e inseguranças.

A criação de uma sociedade de risco, onde os membros da sociedade possuem uma crescente sensação objetiva e subjetiva de insegurança, incrementada pela mídia, faz com que a sociedade reivindique clame pelo recrudescimento da intervenção punitiva.

No entanto, o sistema jurídico não estava preparado para os riscos advindos do avanço científico-tecnológico que geraram novas demandas que até então não existiam. Essas mudanças, contudo, enfraquecem não apenas o Poder Público, mas todo seu aparato de garantias em que se inclui o Direito.

O recrudescimento legislativo na esfera penal utilizado de forma isolada é inócuo, pois a política criminal deve estar articulada com políticas públicas, pois o exacerbamento das formas de punição em nada reduzem as taxas de violência, devendo-se evitar a visão deturpada do Direito Penal e fugir da força do simbolismo.

\section{REFERÊNCIAS}

BARATTA, Alessandro. Criminologia y Sistema Penal. Montevideo/Buenos Aires: Editorial B de F, 2004.

BATISTA, Nilo. Novas Tendências do Direito Penal. Rio de Janeiro: Revan, 2004.

BAUMAN, Zygmunt. Globalização: as consequências humanas. Rio de Janeiro: Jorge Zahar, 1999.

BECK, Ulrich. Sociedade de Risco - Rumo a uma outra modernidade. Tradução Sebastião Nascimento. São Paulo: Editora 34, 2011.

BOURDIEU, Pierre. Sobre a televisão. Tradução de Maria Lúcia Machado. Rio de Janeiro: Jorge Zahar, 1997.

BUERGO, Blanca Mendoza. El Derecho Penal en la Sociedad del Riesgo. Madrid: Civitas, 2001.

CALlegari, André Luís. et al. Direito Penal e Globalização: Sociedade do Risco, Imigração Irregular e Justiça Restaurativa. Porto Alegre: Livraria do Advogado, 2011.

CALLEGARI, André Luís. WERMUTH, Maiquel Ângelo Dezordi. Sistema Penal e Política Criminal. Porto Alegre, Livraria do Advogado, 2010.

GARCIA, José Angel Brandariz. Política Criminal de la Exclusión. Granada: Comares, 2007. 
MOLINA, Antonio García-Pablos de. Hacia uma "redefinición" del rol de la víctima en la criminologia y en el sistema legal. Estúdios penales en memória del Profesor Agustín Fernades Albor. Santiago de Compostela: Universidad de Santiago de Compostela, 1989.

MORAES, Alexandre Rocha Almeida de. Direito Penal do Inimigo: a terceira velocidade do direito penal. Curitiba: Juruá, 2009.

RIPOLLÉS, José Luis Díez. La Política Criminal en la Encrucijada. Montevideo- Buenos Aires: Editorial IbdeF, 2007.

SÁNCHEZ, Jesús-María Silva. A Expansão do Direito Penal: aspectos da política criminal nas sociedades pós-industriais. Tradução de Luiz Otávio de Oliveira Rocha. São Paulo: Revista dos Tribunais, 2002. 11. V.

WERMUTH, Maiquel Ângelo Dezordi. Medo e Direito Penal: Reflexos da expansão punitiva na realidade brasileira. Porto Alegre: Livraria do Advogado, 2011. 